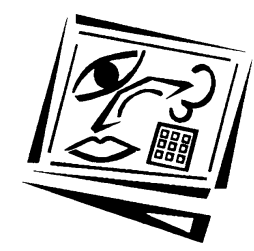

\title{
IT skills of university undergraduate students enrolled in a first year unit
}

\author{
Kieran F. Lim and Jeanne Lee \\ School of Biological and Chemical Sciences, Deakin University
}

\begin{abstract}
The use of computers is becoming more widespread in education and in the wider workforce. This communication reports the results of a survey of first year undergraduate students at Deakin University, conducted at the beginning of the 2000 academic year. The high penetration of IT usage in this university sample is similar to that of a recent survey of school students conducted by Meredyth et al. [Real Time: Computers, Change and Schooling, DETYA, Canberra, 1999]. The present study indicates that the level of IT skills is variable. There is an urgent need for IT training for university students in order to achieve successful learning outcomes using IT and to satisfy the needs of future employers.
\end{abstract}

\section{Introduction}

The use of computers is becoming more widespread in education and in the wider workforce. Ten years ago, the Australian Education Council (1990) stated:

\begin{abstract}
Computers and calculators provide students with opportunities ... at a younger age than they might otherwise have ... [School] students should have sufficient experience of calculators and computers ... to be able to make informed decisions about whether to use them .... and to use them efficiently when they wish to do so.
\end{abstract}

More recently, Zielinski and Swift (1997) listed desirable IT skills that every chemistry graduate should possess (see Table 1). While this list may vary slightly from discipline to discipline (Pennell, 1996; Blackhurst et al., 1997; Lim, 2000), it is clear that graduates (or university level students) who do not possess key IT skills in the use of word processors, spreadsheets, electronic communication and the World Wide Web will be disadvantaged in their careers (Australian Government Publishing Service, 1997). 
Table 1: Desirable IT skills that every chemistry graduate should possess

Zielinski and Swift's list of desirable IT skills (Zielinski and Swift, 1997)

- Electronic record keeping

- Word Processing

- Spreadsheets

- Databases. This also includes the use of databases in the form of personal bibliographic reference lists.

- Programming. This is rather controversial (O'Haver, 1993; Zielinski and Swift, 1997)

- Instrument interfacing. This is important in some but not all areas of chemistry.

- Information retrieval using the World Wide Web.

- Information retrieval from electronic journals, patent information and other specialised databases.

Other desirable IT skills (Pennell, 1996; Blackhurst et al., 1997; Lim, 2000)

- Electronic communication via email, computer conferencing, etc.

- Use of specialised software for drawing chemical structures.

- Molecular modeling software. This is important in some but not all areas of chemistry.

There is an expectation in the Australian society that our school leavers are a generation of computer literate individuals. This is evidenced, inter alia, by the fact that many if not most advertisements now carry a web address or URL. The expectation has been engendered by state and federal government reports (propaganda?) of increased spending on computers and computer infrastructure in primary and secondary schools. Indeed, many non-government schools actively tell prospective parents that ownership and use of computers is compulsory for their students. This (unchallenged) assumption that all school leavers should be highly computer literate and they either are, or in the very near future will be, highly computer literate has driven the installation of open access computer laboratories in universities, institutes of technical and further education (TAFE) and even in municipal libraries.

For example, in the mid-1990s, the Australian Federal Government funded several centres under the Uniserve Australia scheme, which inter alia fostered the use of IT in Autralian universities. This expectation and assumption of high computer literacy has been reinforced by a recent 
study by Meredyth et al. (1999) which found that there is a high penetration of "expert computer skills" amongst primary and secondary students (as judged primarily by students' self perception of their skills). Although the extent of penetration of computer skills was only a secondary objective of Meredyth et al. (1999), this has been the aspect of the study which has been summarised in a fact sheet produced by the Australian Bureau of Statistics (Meredyth et al., 2000).

Meredyth et al. (1999) surveyed 222 principals, 1258 teachers and 6213 students throughout Australia. The students are in the final years of primary school (Year 6, Year 7 in some states) and of junior secondary school (Year 10). They investigated students' "participation in various types of activities: how, why, when and where they used information technology". Figure 1 shows the percentage of Year 10 students who have knowledge of "core IT skills" in the areas of Web, email, spreadsheet and word processing usage. Meredyth et al. (1999) also investigated the social, cultural, geographical, and other factors influencing IT usage. However, the study did not address the level of competence. For example, the survey addressed whether students used word processing programs, but did not address the question of how skilled those students were in their use (Meredyth et al. (1999) also investigated knowledge of other "core IT skills", but these other skills are not relevant to the present study).

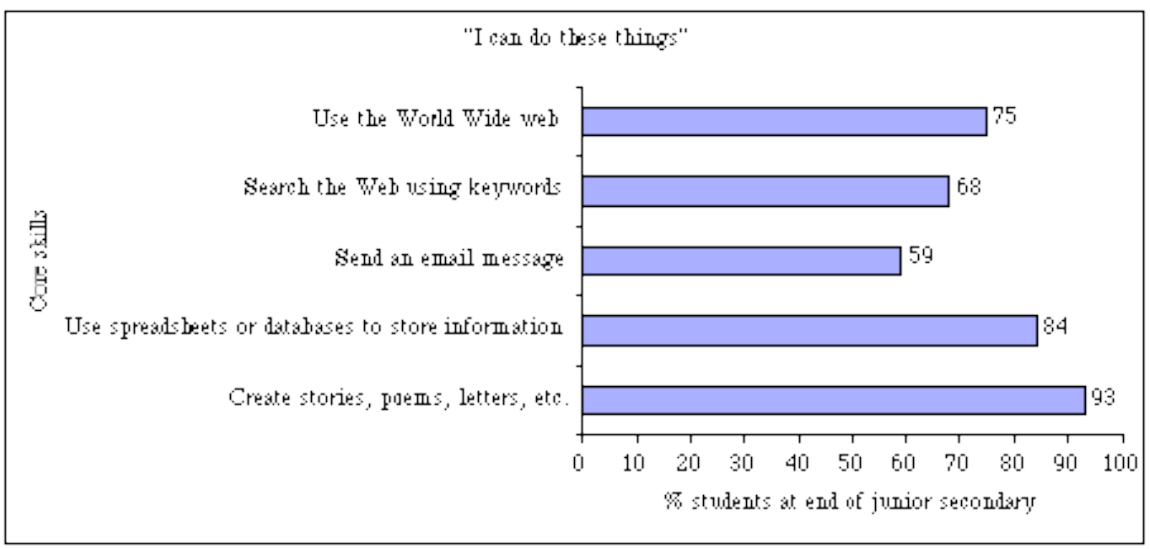

Figure 1: Percentage of students at Year 10 who responded "I can do these things" in the core IT skill areas of Web, email, spreadsheet and word processing usage (Meredyth et al., 1999). 
At the start of the current academic year, we conducted a "quick and dirty" survey of some university undergraduate students enrolled in a first year unit in order to finalise our plan to use IT in aspects of our teaching during 2000. The underlying assumption was that our university undergraduate students are computer literate. It was our expectation that most students would claim knowledge and skills in the use of word processors, spreadsheets, electronic communication and the World Wide Web: we wished to identify the level of IT usage at which we should start. A secondary objective was to quantity the (expected) minority that lacked those skills in order that we could plan remedial assistance.

Surprisingly, this assumption proved to be invalid. Since authors are not aware of any recent similar survey elsewhere in Australia, we present this study as a preliminary finding in order to challenge other universities to conduct similar (and more detailed) surveys.

\section{The survey design}

The survey was designed to investigate the level of students' knowledge in the usage of IT. Survey response options covered the range from no awareness to varying levels of expertise (see Appendix):
a. No awareness or knowledge;
b. Awareness but no knowledge of usage;
c. Knowledge to use the technology;
d, e. Expert knowledge to use the technology.

The survey was distributed to students enrolled in SBC 111 Chemistry A within the School of Biological and Chemical Sciences at Deakin University (Geelong campus). The student profile of this cohort is:

- $70 \%$ enrolled in first year: direct entry from high school;

- $7 \%$ enrolled in first year: non-direct entry from high school (ie, mature age students);

- $23 \%$ have some prior university study: ie, they are enrolled in second year or third year university studies, or a second degree.

While other Australian universities (and even different faculties within Deakin University) may have a different mix of students, based on their enrolment histories, there is no particular reason to believe that this cohort of students would have significantly lower IT skills from any other cohort 
of students enrolled in a first year unit at any Australian university. In fact, we might expect a cohort of science students to have higher IT skills than most students.

Students were permitted approximately 5 minutes to complete the survey during the first class of the 2000 academic year. Students were asked to choose the response to each statement that best described themselves and to complete the survey in numerical order, ie, not to change an earlier response after encountering a later statement or question. 84 surveys were distributed:

- 80 surveys were returned with all questions completed;

- 1 survey with questions 1-15 completed;

- 1 survey with questions 1-8 completed; and

- 2 surveys were returned with no questions completed (one of these incomplete surveys was returned by a person who was accompanying his partner to the class, but who was not, himself, enrolled in the class.)

\section{Analysis and discussion}

Of the 1383 individual responses received, 8 were ambiguous. In these 8 cases, students had circled both response (b: no knowledge) and response (c: knowledge) for a particular statement/question: these 8 responses are counted as response (c: knowledge) in all subsequent analyses. ${ }^{1}$

Most students have easy access to computers either at home or in the student residences; only 2 students $(2 \%)$ had no easy access to computers (survey question 1) at home or in the student residences. Note that question 1 did not ask about access to computers in the university's open access laboratories.

Figure 2 shows the percentage of university students who have knowledge (responses c, d or e) of core IT skills in the areas of Web, email, spreadsheet and word processing usage. The percentages of university students who have knowledge of Web and email usage is significantly

1 Standard surveying methods would disregard these ambiguous responses. Since, we are effectively using a "proof by contradiction" (from the discipline of mathematical logic) to disprove the primary assumption of computer literacy, the interpretation of these responses as the higher of the two possibilities is equivalent to extending the limit of a "greatest lower bound" for the set of students who have the IT skills in question. 
higher than that of the Year 10 students in the survey by Meredyth et al. (1999). This may be due to the use of the Web in collecting information for research projects in Years 11 and 12 (eg, the Common Assessment Tasks in the Victorian Certificate of Education) and/or the minority of students who have had some prior university study. Unfortunately, the survey did not ask about enrolment status so no cross tabulation can be made between the results of the survey and the enrolment history of the students. The percentages of students with knowledge of spreadsheet and word processing usage is similar in both samples.

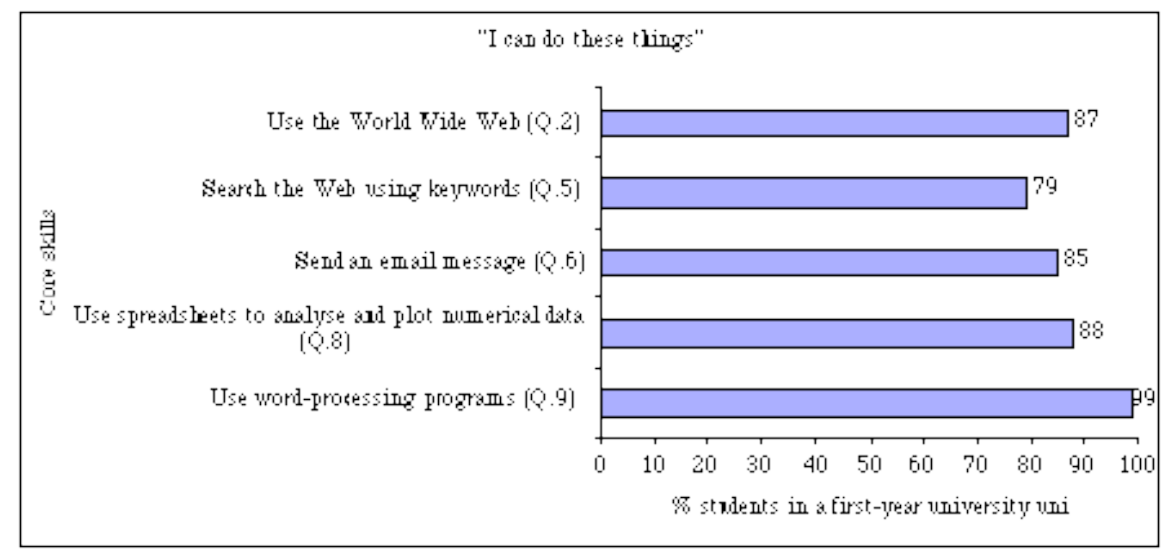

Figure 2: Percentage of students in a first year university unit who responded "I can do these things" in the core IT skill areas of Web, email, spreadsheet and word processing usage.

The average skill level for each student can be estimated by giving a numerical score ranging from 1 for response (a) to 5 for response (e) for questions 2-12, 14 and 15, omitting the questions on computer access, chemical structures, computer conferencing and the university computer laboratories. The resultant scores were sorted into bins centred at 1.0, 1.5, $2.0, \ldots, 5.0$ (Figure 3). Most students (83\%) have scores around 2.5-3.0: knowing or almost knowing how to use the technology. 52\% of students have scores between 1.75 and 2.75 (bins centred at 2.0 and 2.5), indicating that their overall computer skill is slightly less than "I know how to use ".

This lack of specific skills is also evidenced in the students' knowledge for printing from computers to hardcopy. Presumably all know how to use the print function, but most students $(55 \%)$ do not know how to print more than one computer "page" to a single piece of hardcopy (survey 
question 14). A significant number (15\%) had never heard of this print feature.

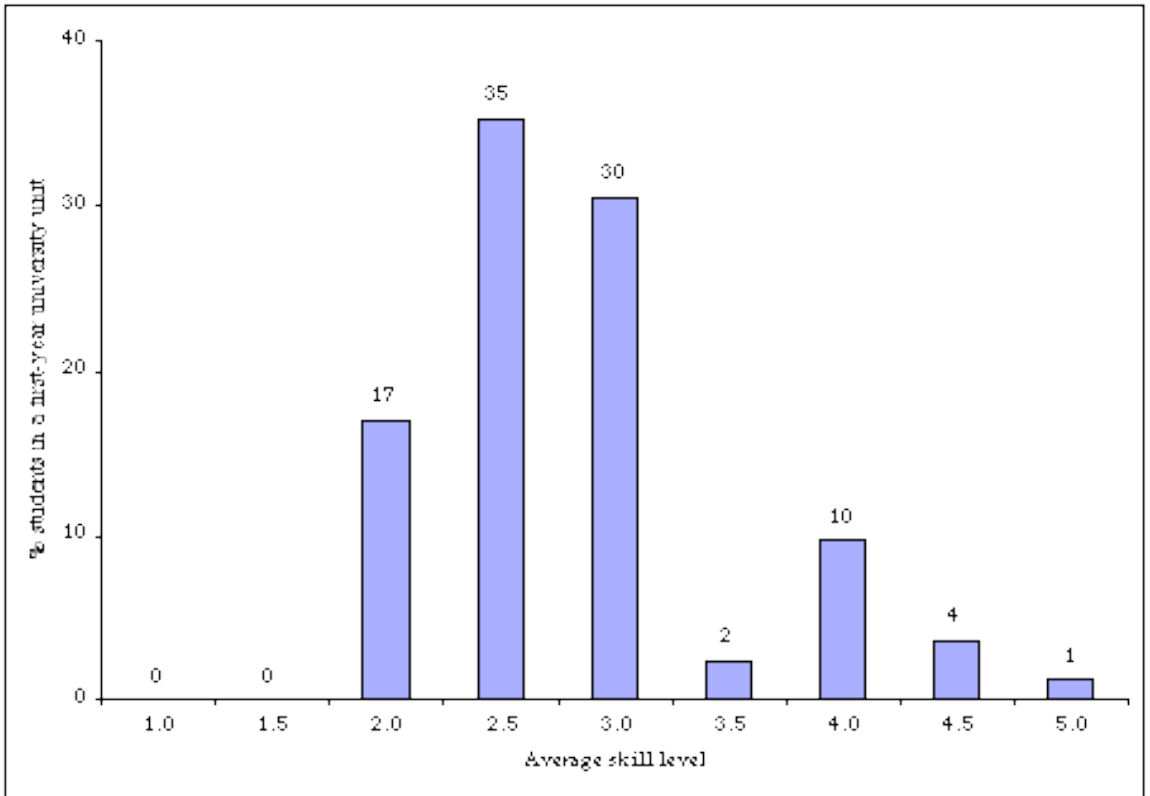

Figure 3: Percentage of students in a first year university unit with a particular average skill level. Numerical scores: $1.0=$ no awareness; $2.0=$ no knowledge; $3.0=$ knowledge; $4.0=$ expert knowledge; $5.0=$ sufficient expert knowledge to teach others.

The cross tabulations ("corelations") between responses for different questions/statements yield much more useful information. Tables 2-12 present cross tabulation tables where a specific skill (eg use of superscripts / subscripts) is cross tabulated with the general skill (eg use of word processing). Entries in the upper right of the cross tabulation tables represent students whose level of specific skill is less than the level of the general skill.

Tables 2-6 show that of the 71 students $(87 \%)$ who know how to use the Web (ie responses (c), (d) and (e) in Question 2):

- 21 students (26\% of the total survey) do not know how to use Web addresses (URLs);

- 7 students (9\% of the total survey) have never heard of Web addresses (URLs); 
- 25 students (30\% of the total survey) do not know how to download files from the Web;

- 52 students (64\% of the total survey) do not know how to read PDF files.

Furthermore, of the 47 students (58\%) who know how to download files from the Web:

- 29 students (36\% of the total survey) do not know how to read PDF files.

Table 2: Cross tabulation of knowledge about URLs and general Web usage.

\begin{tabular}{|c|c|c|ccccc|c|}
\cline { 2 - 9 } \multicolumn{1}{c|}{} & \multicolumn{7}{c|}{ Q.2: knowledge of Web usage } \\
\hline \multirow{3}{*}{$\begin{array}{c}\text { Q.3: knowledge } \\
\text { of URLs }\end{array}$} & know & $\mathrm{a}$ & $\mathrm{b}$ & $\mathrm{c}$ & $\mathrm{d}$ & $\mathrm{e}$ & totals \\
\cline { 2 - 9 } & $\mathrm{a}$ & & 5 & 7 & & & 12 \\
\cline { 2 - 9 } & $\mathrm{b}$ & & 4 & 14 & & & 18 \\
$\mathrm{c}$ & & 2 & 39 & 2 & & 43 \\
& $\mathrm{~d}$ & & & & & 3 & 1 & 4 \\
& $\mathrm{e}$ & & & & & & 5 & 5 \\
\hline & totals & 0 & 11 & 60 & 5 & 6 & 82 \\
\hline
\end{tabular}

Table 3: Cross tabulation of knowledge about downloading files and general Web usage.

\begin{tabular}{|l|c|c|ccccc|c|}
\cline { 2 - 9 } \multicolumn{1}{c|}{} & \multicolumn{7}{c|}{ Q.2: knowledge of Web usage } \\
\hline Q.4: knowledge of & know & $\mathrm{a}$ & $\mathrm{b}$ & $\mathrm{c}$ & $\mathrm{d}$ & $\mathrm{e}$ & totals \\
\cline { 2 - 9 } downloading files & $\mathrm{a}$ & & 2 & & & & 2 \\
& $\mathrm{~b}$ & & 8 & 25 & & & 33 \\
& $\mathrm{c}$ & & 1 & 33 & 1 & 1 & 36 \\
& $\mathrm{~d}$ & & & 1 & 3 & & 4 \\
& $\mathrm{e}$ & & & 1 & 1 & 5 & 7 \\
\hline & totals & 0 & 11 & 60 & 5 & 6 & 82 \\
\hline
\end{tabular}

Table 4: Cross tabulation of knowledge about keyword searches and general Web usage.

\begin{tabular}{|l|c|c|ccccc|c|}
\cline { 2 - 9 } \multicolumn{1}{c|}{} & \multicolumn{7}{c|}{ Q.2: knowledge of Web usage } \\
\hline Q.5: knowledge of & know & $\mathrm{a}$ & $\mathrm{b}$ & $\mathrm{c}$ & $\mathrm{d}$ & $\mathrm{e}$ & totals \\
\cline { 2 - 9 } keyword searches & $\mathrm{a}$ & & 2 & 2 & & & 4 \\
& $\mathrm{~b}$ & & 6 & 7 & & & 13 \\
& $\mathrm{c}$ & & 3 & 44 & 1 & & 48 \\
& $\mathrm{~d}$ & & & 6 & 3 & 1 & 10 \\
& $\mathrm{e}$ & & & 1 & 1 & 5 & 7 \\
\hline & totals & 0 & 11 & 60 & 5 & 6 & 82 \\
\hline
\end{tabular}


Table 5: Cross tabulation of knowledge about reading PDF files and general Web usage.

\begin{tabular}{|c|c|c|c|c|c|c|c|}
\hline & \multicolumn{7}{|c|}{ Q.2: knowledge of Web usage } \\
\hline \multirow{7}{*}{$\begin{array}{l}\text { Q.15: knowledge of } \\
\text { reading PDF files }\end{array}$} & know & a & $\mathrm{b}$ & $\mathrm{c}$ & d & e & totals \\
\hline & $a$ & & 7 & 19 & 1 & 1 & 28 \\
\hline & b & & 4 & 20 & & & 24 \\
\hline & c & & & 9 & 2 & 3 & 14 \\
\hline & d & & & & 2 & 1 & 3 \\
\hline & $\mathrm{e}$ & & & 1 & & 1 & 2 \\
\hline & totals & 0 & 11 & 59 & 5 & 6 & 81 \\
\hline
\end{tabular}

Table 6: Cross tabulation of knowledge about reading PDF files and downloading files from the Web.

\begin{tabular}{|c|c|c|c|c|c|c|c|}
\hline $\begin{array}{l}\text { Q.15: knowledge of } \\
\text { reading PDF files }\end{array}$ & \multicolumn{7}{|c|}{ Q.4: knowledge of downloading files } \\
\hline \multirow{7}{*}{$\begin{array}{l}\text { Q.15: knowledge of } \\
\text { reading PDF files }\end{array}$} & know & $a$ & $\mathrm{~b}$ & c & $\mathrm{d}$ & $\mathrm{e}$ & totals \\
\hline & $a$ & 1 & 23 & 12 & 1 & 1 & 38 \\
\hline & $\mathrm{b}$ & 1 & 8 & 15 & & & 24 \\
\hline & $\mathrm{c}$ & & 1 & 8 & 1 & 4 & 14 \\
\hline & $\mathrm{d}$ & & & & 2 & 1 & 3 \\
\hline & $\mathrm{e}$ & & & 1 & & 1 & 2 \\
\hline & totals & 2 & 32 & 36 & 4 & 7 & 81 \\
\hline
\end{tabular}

Note that these statistics are for the sub-set of students who already have knowledge in the general skill area. The implications are alarming. Although most students claim to know how to use the Web, university teaching staff cannot say

Look at the information at (eg) http: / / www2.deakin.edu.au/biolgya /

and then expect a successful learning outcome, because more than one quarter of the class will not be able to use the URL to locate that Web site. Furthermore, since it is common practice to put electronic documents on the Web in portable document format (PDF), even if students could find the file and download the information, most will not be able to read the file! Given the increasing use of Web based teaching resources: (O'Haver, 1993; Krieger, 1995; Long and Zielinski, 1996; Pennell, 1996; 1997; Blackhurst et al., 1997; Freeman, 1997; Alexander and McKenzie, 1998; Brown and Duguid, 1998; Fernandez, 1998; McCann et al., 1998; Glaser and Poole, 1999; Middleton, 1999; Paulisse and Polik, 1999; Pence, 1999) are a minute sample, there is an urgent need for IT training on use of the Web for university students. 
Table 7 shows that that of the 70 students (85\%) who know how to use email:

- 37 students ( $45 \%$ of the total survey) do not know how to use email attachments.

Table 7: Cross tabulation of knowledge about email attachments and general email usage.

\begin{tabular}{|l|c|c|ccccc|c|}
\cline { 2 - 9 } \multicolumn{1}{c|}{} & \multicolumn{7}{c|}{ Q.6: knowledge of email usage } \\
\hline Q.7: knowledge of & know & $\mathrm{a}$ & $\mathrm{b}$ & $\mathrm{c}$ & $\mathrm{d}$ & $\mathrm{e}$ & totals \\
\cline { 2 - 9 } email attachments & $\mathrm{a}$ & 1 & 3 & 3 & & & 7 \\
& $\mathrm{~b}$ & & 8 & 30 & 2 & 2 & 42 \\
& $\mathrm{c}$ & & & 17 & 3 & 2 & 22 \\
& $\mathrm{~d}$ & & & & 6 & & 6 \\
& $\mathrm{e}$ & & & & & 5 & 5 \\
\hline & totals & 1 & 11 & 50 & 11 & 9 & 82 \\
\hline
\end{tabular}

Email, computer conferencing and instructional management systems are major innovations in flexible learning (Alexander and McKenzie, 1998; McCann et al., 1998). (Also note that $80 \%$ of students did not know how to use computer conferencing: survey question 16.) These technologies also have the capacity for rapid submission of work and dissemination of feedback to students in distance education. However, the realisation of this promise depends on the ability to send attached documents. This survey shows that a significant number of students in the sample do not have the requisite skill level to make full use of email and computer conferencing for electronic submission of work.

The work of Meredyth et al. (1999) and the current survey indicate that most students $(>90 \%)$ are able to use word processing software. Tables 811 indicate that the level of skill is not uniformly high. Of the 80 students (99\% of the total survey) who know how to use word processing:

- 13 students (16\% of the total survey) do not know how to use superscripts/subscripts;

- 3 students (4\% of the total survey) have never heard of superscripts/subscripts. This result is most surprising in a cohort of chemistry students since chemical formulae are always written using a mixture of normal text, superscripts and subscripts: this can be seen in any chemistry text (even in high school);

- 18 students ( $23 \%$ of the total survey) do not know how to use special characters and symbols;

- 43 students ( $54 \%$ of the total survey) do not know how to insert equations into documents; and 
- 63 students (79\% of the total survey) do not know how to insert chemical structures into documents.

Table 8: Cross tabulation of knowledge about superscripts/subscripts and general word processing.

\begin{tabular}{|c|c|c|c|c|c|c|c|}
\hline $\begin{array}{l}\text { Q.10: knowledge of } \\
\text { superscripts / } \\
\text { subscripts }\end{array}$ & \multicolumn{7}{|c|}{ Q.9: knowledge of word processing } \\
\hline \multirow{7}{*}{$\begin{array}{l}\text { Q.10: knowledge of } \\
\text { superscripts / } \\
\text { subscripts }\end{array}$} & know & a & $\mathrm{b}$ & $\mathrm{C}$ & $\mathrm{d}$ & $\mathrm{e}$ & totals \\
\hline & $\mathrm{a}$ & & & 3 & & & 3 \\
\hline & b & & & 8 & 2 & & 10 \\
\hline & c & & 1 & 38 & 5 & 1 & 45 \\
\hline & d & & & 3 & 9 & 1 & 13 \\
\hline & $\mathrm{e}$ & & & & 2 & 8 & 10 \\
\hline & totals & 0 & 1 & 52 & 18 & 10 & 81 \\
\hline
\end{tabular}

Table 9: Cross tabulation of knowledge about special letters/symbols and general word processing.

\begin{tabular}{|c|c|c|c|c|c|c|c|}
\hline & \multicolumn{7}{|c|}{ Q.9: knowledge of word processing } \\
\hline \multirow{7}{*}{$\begin{array}{l}\text { Q.11: knowledge of } \\
\text { special letters / } \\
\text { symbols }\end{array}$} & know & a & $\mathrm{b}$ & $\mathrm{c}$ & $\mathrm{d}$ & $\mathrm{e}$ & totals \\
\hline & a & & & 1 & & & 1 \\
\hline & b & & & 14 & 2 & 1 & 17 \\
\hline & C & & 1 & 34 & 3 & 1 & 39 \\
\hline & d & & & 3 & 7 & 3 & 13 \\
\hline & $\mathrm{e}$ & & & & 6 & 5 & 11 \\
\hline & totals & 0 & 1 & 52 & 18 & 10 & 81 \\
\hline
\end{tabular}

Table 10: Cross tabulation of knowledge about equations and general word processing.

\begin{tabular}{|c|c|c|c|c|c|c|c|}
\hline $\begin{array}{c}\text { Q.12: knowledge of } \\
\text { equations }\end{array}$ & \multicolumn{7}{|c|}{ Q.9: knowledge of word processing } \\
\hline \multirow{7}{*}{$\begin{array}{c}\text { Q.12: knowledge of } \\
\text { equations }\end{array}$} & \multirow{6}{*}{$\begin{array}{c}\text { know } \\
\mathrm{a} \\
\mathrm{b} \\
\mathrm{c} \\
\mathrm{d} \\
\mathrm{e}\end{array}$} & \multirow[t]{2}{*}{$\mathrm{a}$} & $\mathrm{b}$ & \multirow{2}{*}{$\begin{array}{l}\mathrm{c} \\
2\end{array}$} & \multirow[t]{2}{*}{$\mathrm{d}$} & \multirow[t]{2}{*}{$\mathrm{e}$} & \multirow{2}{*}{$\begin{array}{c}\text { totals } \\
3\end{array}$} \\
\hline & & & 1 & & & & \\
\hline & & & 1 & 35 & 3 & 3 & 42 \\
\hline & & & & 15 & 6 & 3 & 24 \\
\hline & & & & 1 & 3 & 1 & 5 \\
\hline & & & & & 4 & 3 & 7 \\
\hline & totals & 0 & 1 & 52 & 18 & 10 & 81 \\
\hline
\end{tabular}

Some disciplines may not require the use of superscripts/subscripts, special characters/symbols, equations and/or technical diagrams in their written work, but some or all of these features are required in many of the scientific and technologically based disciplines. Hence there may be a need 
for further IT training of university students, depending on their enrolled specialty.

Table 11: Cross tabulation of knowledge about chemical structures and general word processing.

\begin{tabular}{|c|c|c|ccccc|c|}
\cline { 2 - 8 } \multicolumn{1}{c|}{} & \multicolumn{8}{c|}{ Q.9: knowledge of word processing } \\
\hline Q.13: knowledge of & & $\mathrm{a}$ & $\mathrm{b}$ & $\mathrm{c}$ & $\mathrm{d}$ & $\mathrm{e}$ & totals \\
\cline { 2 - 9 } chemical structures & $\mathrm{a}$ & & \multicolumn{3}{c|}{13} & 1 & 1 & 15 \\
& $\mathrm{~b}$ & & 1 & 32 & 9 & 7 & 49 \\
& $\mathrm{c}$ & & & 6 & 7 & 2 & 15 \\
& $\mathrm{~d}$ & & & & & 1 & & 1 \\
& $\mathrm{e}$ & & & & & & 0 \\
\cline { 2 - 9 } & totals & 0 & 1 & 52 & 18 & 10 & 81 \\
\hline
\end{tabular}

Every cross tabulation table, except Table 3 (keyword searches versus Web usage) shows that there are significantly more students in the upper right of the matrix than the lower left: the level of knowledge about specific features of IT usage is lower that the perceived overall level of knowledge.

Meredyth et al. (1999) has found that the penetration of IT usage is higher among primary school students than secondary school students. The tertiary education sector can reasonably expect a higher proportion of computer literate undergraduate students over the next 5-10 years. However, there may still be a significant minority of students who lack specific IT skills. Some institutions, which have a high number of mature age students, may continue to have a significant number of students who lack even general IT skills.

Finally, students will benefit from a good orientation program. Obviously the program at Deakin University can be improved in future years since about half the students did not know how to use the university's open access laboratories (survey question 17): this may also be true at other institutions. On the other hand, this may not be a problem since most students have easy access to a computer at home or in the residences (survey question 1).

\section{Recommendations}

The following is a non-exhaustive list of practices which will improve teaching and learning. 
1. All Australian universities should undertake similar (and more detailed) surveys to quantify the scope and level of IT knowledge and skill within their institutions in order to inform their strategic planning for both IT infrastructure and Teaching and Learning.

2. Some class time should be used to show students how to access an unlinked URL. Class handouts should include (printed) information on how to access unlinked URLs.

3. Where possible, there should be links from subject/unit home pages to all the URLs mentioned in class or in class handouts.

4. Students should be given (printed) instructions on how to obtain and load Acrobat Reader. Some class time should be used to show students how to save, read and print (!) portable document format (PDF) files.

5. Some class time should be spent on introducing students to the use of particular software packages. For example, 5 minutes would be sufficient to show students how to enter data and draw a graph using Microsoft Excel or a similar spreadsheet program. The aim here is not to teach students how to use the package but to demonstrate its use and then to refer students to various texts such as Duffy (Duffy, 2000) for more detailed instruction.

6. Conversely, if university teaching staff are unwilling to use class time demonstrating the use of software packages, the assessment procedures should not mandate the use of such software.

The provision of printed instructions is essential in the case of off campus students who may face the double disadvantage of difficulty of obtaining IT assistance and usually being less computer literate because many are older than on campus students.

\section{Summary and conclusions}

Most students have some reasonable computer skills at the start of their university studies, but the level of skill is not uniformly high. Although most students may have experience using Web browsers and email, they may not be able to use Web addresses or to send (or receive) attachments; while they can type using word processing packages, they often have difficulty with superscripts, subscripts and (scientific) fonts.

The survey reported here is a small survey and cannot be considered definitive. Nevertheless, to the best of our knowledge, it is the only study of its kind which has recently investigated the IT skill level of 
undergraduate university students. The overall trends are indicative and worrying. University teachers cannot assume IT competency amongst their students. This may compromise the effectiveness of "new technologies" which are increasingly used in teaching and learning. University teachers need to reassess the use of PDF files and other technologies in their teaching. For example, this survey shows that a significant number of students in the sample do not have the requisite skill level to make full use of email and computer conferencing for electronic submission of work.

The penetration of IT skills among university students, and the level of those IT skills is expected to increase but there may be a significant minority of students who will continue to lack both general and specific IT skills. The situation should be monitored on a year by year basis by more (and more detailed) surveys.

There is an urgent need for IT training for university students in order to achieve successful learning outcomes using IT and to satisfy the needs of future employers.

\section{Acknowledgments}

The authors thank Dr Simon Lewis and Ruth Henderson. This work has been partially funded by the Deakin University Teaching and Staff Development Scheme.

\section{References}

Alexander, S. and McKenzie, J. (1998). An Evaluation of Information Technology Projects for University Learning. Canberra: Australian Government Publishing Service.

Australian Education Council (1990). A National Statement on Mathematics for Australian Schools. Carlton (Vic): Curriculum Corporation (Australia).

Australian Government Publishing Service (1997). Business Use of Information Technology. Canberra: Australian Government Publishing Service.

Blackhurst, A. E., Hales, R. M. and Lahm, E. A. (1997). Using an education server software system to deliver Special Education coursework via the World Wide Web. J. Special Educ. Tech. 13(4), 78-98. [verified 11 Nov 2000] http: / / serc.gws.uky.edu/www/ukat/ topclass/tc.html

Brown, J. S. and Duguid, P., Heldref Corporation (1998). Universities in the digital age. [viewed 1 April 1998, verified 11 Nov 2000]

http: / / www.parc.xerox.com/ops/members/brown/papers/university.html

Duffy, T. (2000). Microsoft Office 2000 Professional. Upper Saddle River, NJ: Prentice Hall. 
Fernandez, A., Ed. (1998). Proceedings of the University Science Teaching and the Web Workshop. Sydney: UniServe Science. [verified 11 Nov 2000] http: / / science.uniserve.edu.au/pubs/procs/wshop3/

Freeman, M. (1997). Flexibility in access, interaction and assessment: The case for web based teaching programs. Australian Journal of Educational Technology, 13(1), 23-39. http: / / cleo.murdoch.edu.au/ajet/ajet13/wi97p23.html

Glaser, R. E. and Poole, M. J. (1999). Organic chemistry online: Building collaborative learning communities through electronic communication. Journal of Chemical Education, 76(5), 699-703.

Krieger, J. H. (1995). Chemistry sites proliferate on the Internet's World Wide Web. Chemical Engineering News, 73, 35-46.

Lim, K. F. (2000). Electronic communication media in the teaching of chemistry. Invited lecture, 11th RACI National Convention, Canberra, Australia.

Long, G. R. and Zielinski, T. J. (1996). Teaching chemistry online: Why it should be done. Trends in Analytical Chemistry, 15, 445.

McCann, D., Christmass, J., Nicholson, P. and Stuparich, J. (1998). Educational Technology in Higher Education. Canberra: Department of Education, Training and Youth Affairs. http:/ / www.detya.gov.au/highered/occpaper/edtech.pdf

Meredyth, D., Russell, N., Blackwood, L., Thomas, J. and Wise, P. (1999). Real Time: Computers, Change and Schooling. Canberra: Department of Education, Training and Youth Affairs. http:/ / www.detya.gov.au/schools/Publications/RealTime.pdf [verified 11 Nov 2000]

Meredyth, D., Russell, N., Blackwood, L., Thomas, J. and Wise, P., Griffith University (2000). Real time: Computers, change and schooling. Report for the Australian Bureau of Statistics. [viewed 22 February 2000, verified 11 Nov 2000] http:/ / www.abs.gov.au/Ausstats / ABS\%40.nsf / 94713ad445ff1425ca25682000192af2 / 627 4d6d26d5ab02aca2568a900154bad!OpenDocument

Middleton, C. A. (1999). Asynchronous computer conferencing in the MBA classroom. In Proceedings of the 32nd Annual Hawaii International Conference on System Sciences. Hawaii: IEEE. http: / / www.yorku.ca/academics / middletn/pubs/hicss.pdf

O'Haver, T. C., University of Maryland (1993). Applications of Technology in Teaching Chemistry. An online computer conference. http: / / www.inform.umd.edu/EdRes/Topic/Chemistry/ChemConference/ [viewed 21 Mar 2000, verified 11 Nov 2000]

Paulisse, K. W. and Polik, W. F. (1999). Use of WWW discussion boards in chemical education. Journal of Chemical Education, 76(5), 704-708.

Pence, L. E. (1999). Cooperative electronic mail: Effective communication technology for introductory chemistry. Journal of Chemical Education, 76(5), 697698. 
Pennell, R., University of Western Sydney (1996). Managing online learning. In Proceedings AusWeb96: The Second Australian WorldWideWeb Conference. http:/ / www.scu.edu.au/sponsored/ausweb/ausweb96/educn/pennell/paper.html [viewed 22 Feb 2000, verified 11 Nov 2000]

UniServe Science (1997). Proceedings of the Computer Assessment Workshop. Sydney: UniServe Science. [verified 11 Nov 2000]

http:/ / science.uniserve.edu.au/pubs/procs/wshop2/

Zielinski, T. J. and Swift, M. L. (1997). What every chemist should know about computers, II. Chem. Educator, 2(3). http: / / journals.springer-ny.com/sam$\mathrm{bin} /$ swilma/cmp.871843766.html [restriced access].

\section{Appendix}

Please circle the response to each statement that best describes yourself.

Please answer the survey in numerical order: do not change an earlier response after encountering a later statement.

1. Some students may have easy access to a computer at home or in the residences.

a. What is a computer?

b. I have heard about computers, but do not have easy access to a computer at home or in the residences.

c. I have easy access to a (shared) computer at home or in the residences.

d. I have my own computer at home or in the residences.

e. I have more than one computer (for my very own!) at home or in the residences.

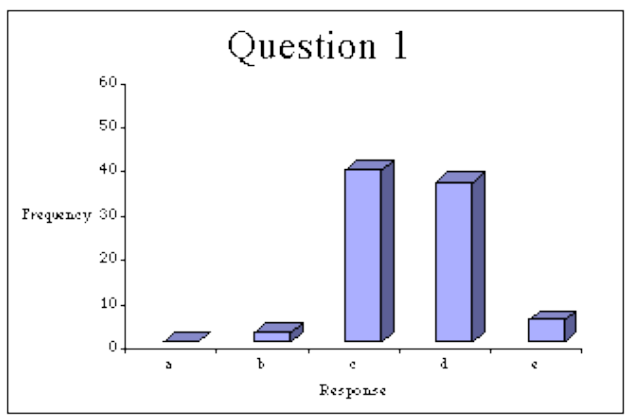

2. Computers can access information on the World Wide Web.

a. I have not heard about the World Wide Web.

b. I have heard about, but do not know how to use the World Wide Web.

c. I know how to use the World Wide Web.

d. I have expert knowledge on how to use the World Wide Web.

e. I have sufficient expert knowledge to teach others how to use the World Wide Web. 


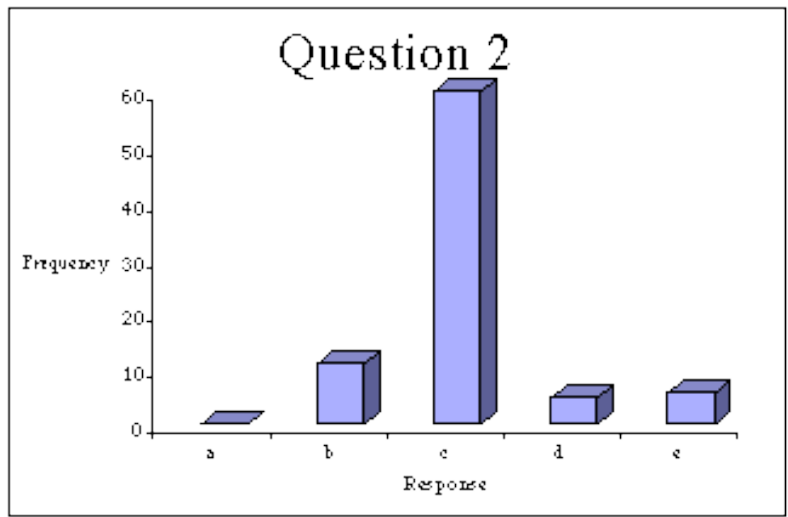

3. http://firstclass.deakin.edu.au/Login/chemistry/ is a World Wide Web address or URL.

a. I have not heard about URLs.

b. I have heard about, but do not know how to use URLs.

c. I know how to use URLs.

d. I have expert knowledge on how to use URLs.

e. I have sufficient expert knowledge to teach others how to use URLs.

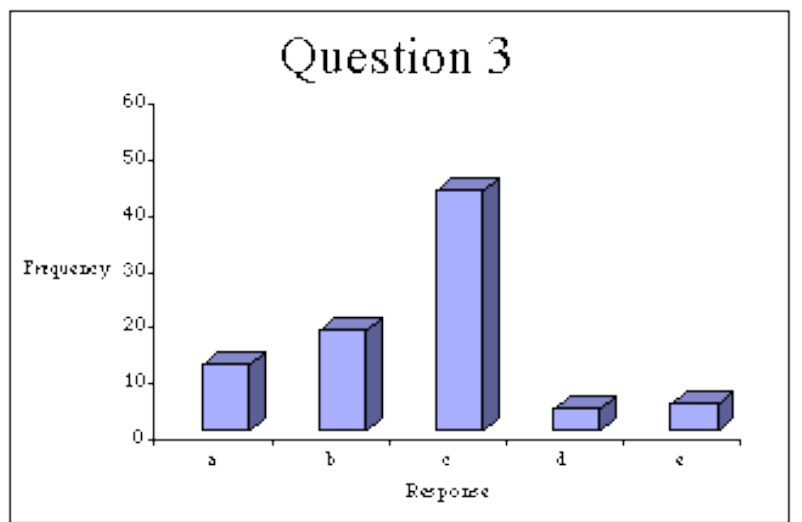

4. Electronic documents or files can be downloaded from the World Wide Web.
a. I have not heard about downloading files on the World Wide Web.
b. I have heard about, but do not know how to do it.
c. I know how to download files.
d. I have expert knowledge on how to download files.
e. I have sufficient expert knowledge to teach others how to download files. 


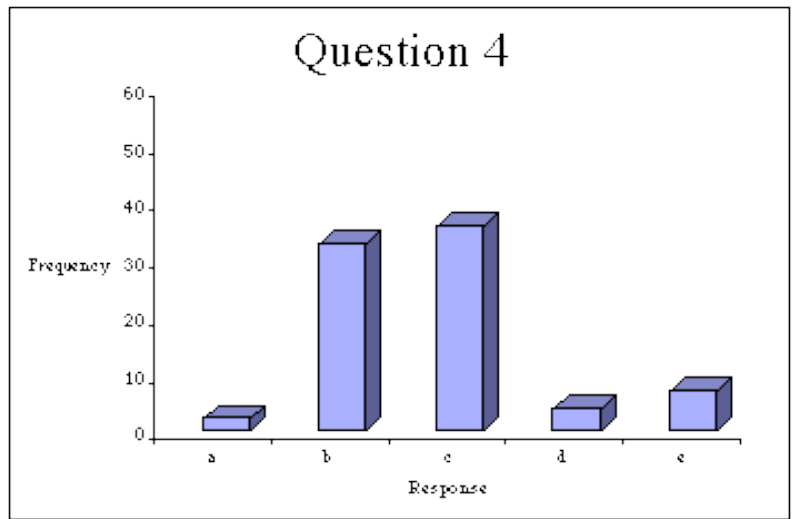

5. The World Wide Web can be searched using keywords.

a. I have not heard about keyword searches on the World Wide Web.

b. I have heard about, but do not know how to use keyword searches..

c. I know how to use keyword searches.

d. I have expert knowledge on how to use keyword searches.

e. I have sufficient expert knowledge to teach others how to use keyword searches.

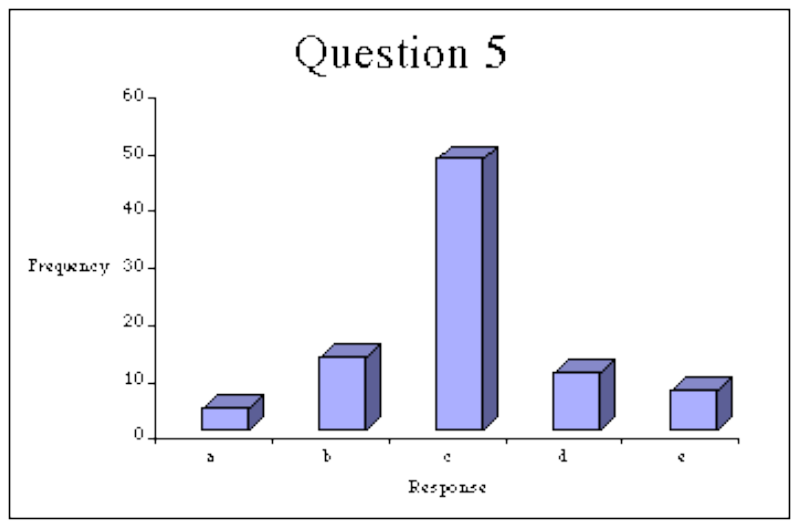

6. The Internet can be used to send and receive electronic mail.

a. I have not heard about electronic mail.

b. I have heard about, but do not know how to use electronic mail.

c. I know how to use electronic mail.

d. I have expert knowledge on how to use electronic mail.

e. I have sufficient expert knowledge to teach others how to use electronic mail. 


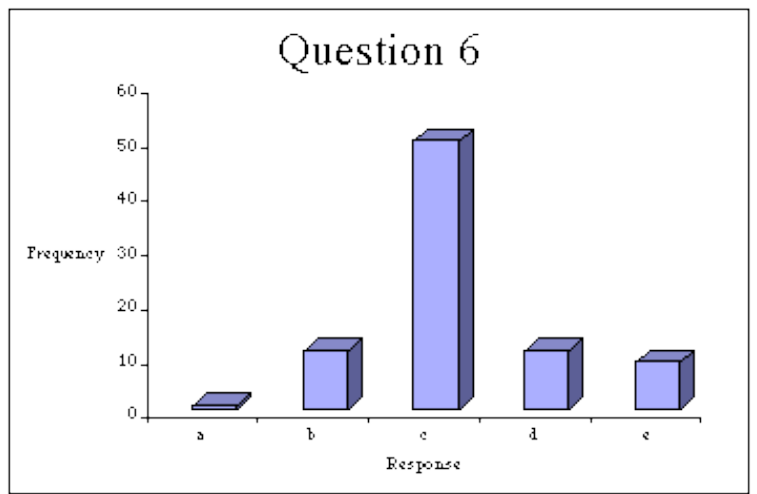

7. Electronic documents or files can be attached to electronic mail.

a. I have not heard about electronic mail attachments.

b. I have heard about, but do not know how to use electronic mail attachments.

c. I know how to use electronic mail attachments.

d. I have expert knowledge on how to use electronic mail attachments.

e. I have sufficient expert knowledge to teach others how to use electronic mail attachments.

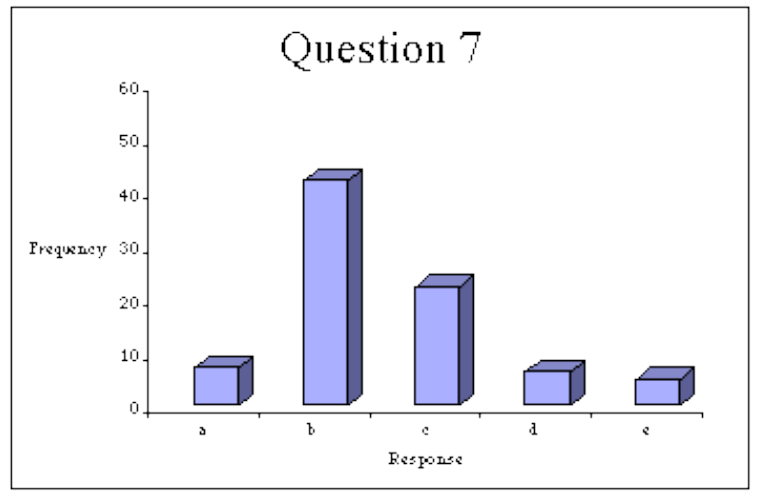

8. Spreadsheet programs (eg EXCEL) can be used to analyse and plot numerical data.

a. I have not heard about spreadsheet programs.

b. I have heard about, but do not know how to use spreadsheet programs.

c. I know how to use spreadsheet programs.

d. I have expert knowledge on how to use spreadsheet programs.

e. I have sufficient expert knowledge to teach others how to use spreadsheet programs. 


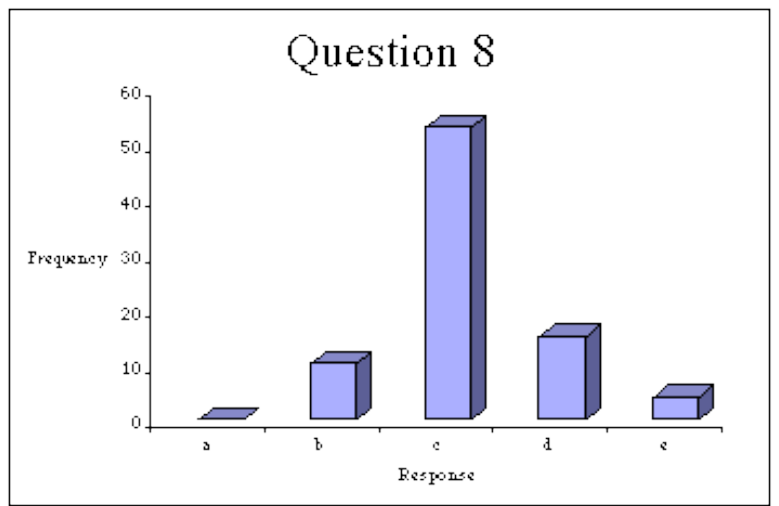

9. Word processing programs (eg WORD, AMI-PRO) can be used to type text based documents.

a. I have not heard about word processing programs.

b. I have heard about, but do not know how to use word processing programs.

c. I know how to use word processing programs.

d. I have expert knowledge on how to use word processing programs.

e. I have sufficient expert knowledge to teach others how to use word processing programs.

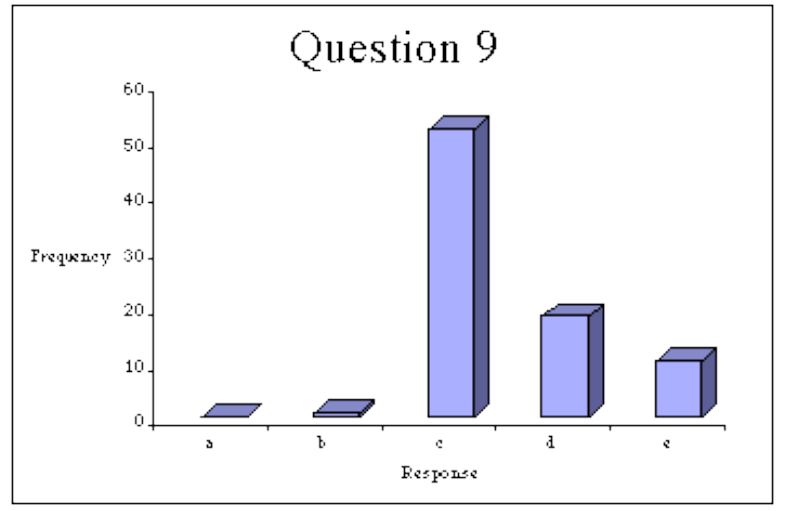

10. Superscripts (superscripts $)$ and subscripts $\left(_{\text {subscripts }}\right)$ can be put in word processing documents.

a. I have not heard about putting superscripts and subscripts in documents.

b. I have heard about, but do not know how to do superscripts and subscripts.

c. I know how to do superscripts and subscripts.

d. I have expert knowledge on how to do superscripts and subscripts.

e. I have sufficient expert knowledge to teach others how to do superscripts and subscripts. 


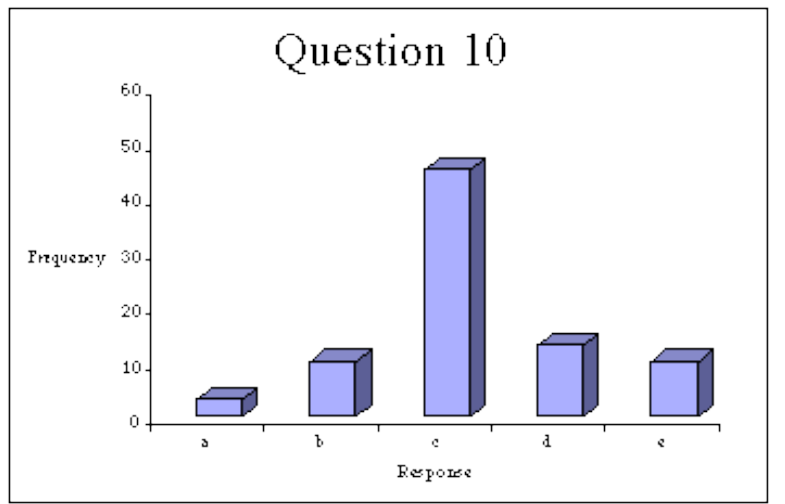

11. Special letters and symbols can be put in word processing documents: eg, $\alpha \beta$ $\gamma \delta \times \rightarrow$.

a. I have not heard about putting special letters and symbols in documents.

b. I have heard about, but do not know how to do special letters and symbols.

c. I know how to do special letters and symbols.

d. I have expert knowledge on how to do special letters and symbols.

e. I have sufficient expert knowledge to teach others how to do special letters and symbols.

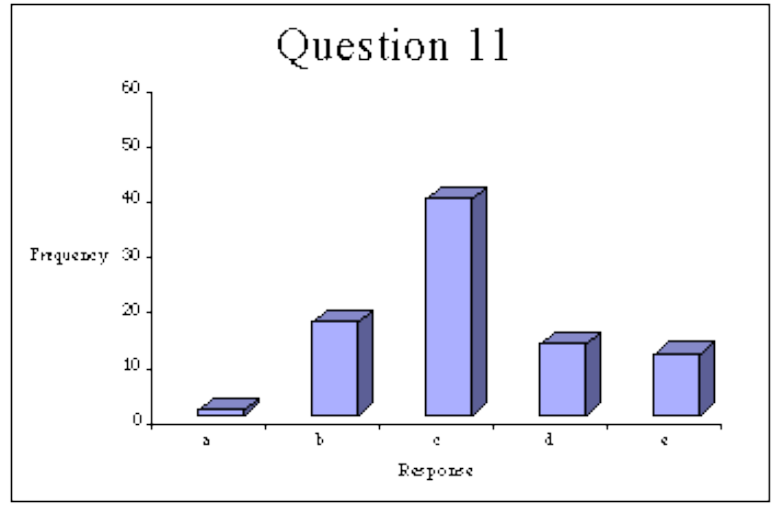

12. Equations can be put in word processing documents.

a. I have not heard about putting equations in documents.

b. I have heard about, but do not know how to do equations.

c. I know how to do equations.

d. I have expert knowledge on how to do equations.

e. I have sufficient expert knowledge to teach others how to do equations. 


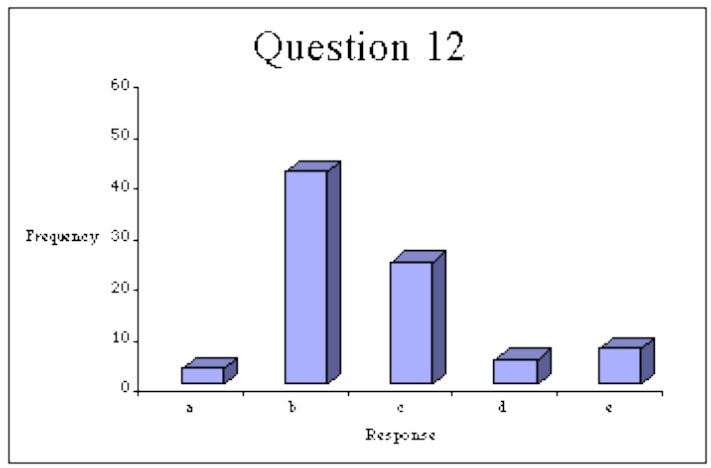

$$
V_{i j}=4 \varepsilon_{i j}\left[\left(\frac{\sigma_{i j}}{r_{i j}}\right)^{12}-\left(\frac{\sigma_{i j}}{r_{i j}}\right)^{6}\right] \quad \mathrm{H}_{\mathrm{H}}^{-1} \mathrm{coOH}
$$

13. Chemical structures can be put in word processing documents.

a. I have not heard about putting chemical structures in documents.

b. I have heard about, but do not know how to do chemical structures.

c. I know how to do chemical structures.

d. I have expert knowledge on how to do chemical structures.

e. I have sufficient expert knowledge to teach others how to do chemical structures.

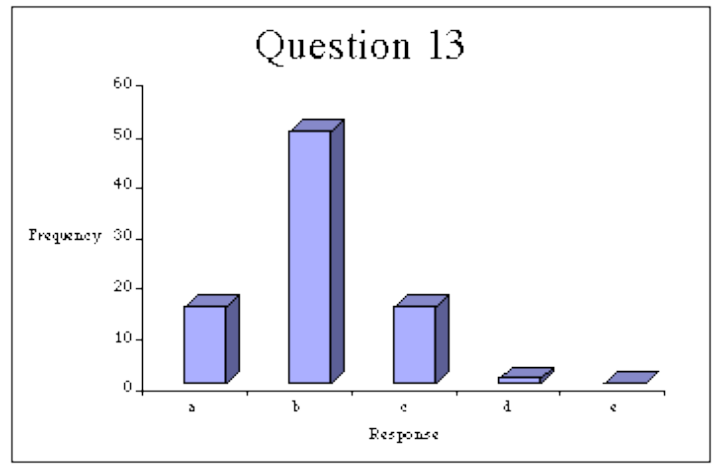

14. It is possible to print two or more "pages" on each sheet of paper.

a. I have not heard about printing two or more "pages" on a sheet of paper.

b. I have heard about, but do not know how to print two or more "pages" on a sheet of paper.

c. I know how to print two or more "pages" on a sheet of paper.

d. I have expert knowledge on how to print two or more "pages" on a sheet of paper.

e. I have sufficient expert knowledge to teach others how to print two or more "pages" on a sheet of paper. 


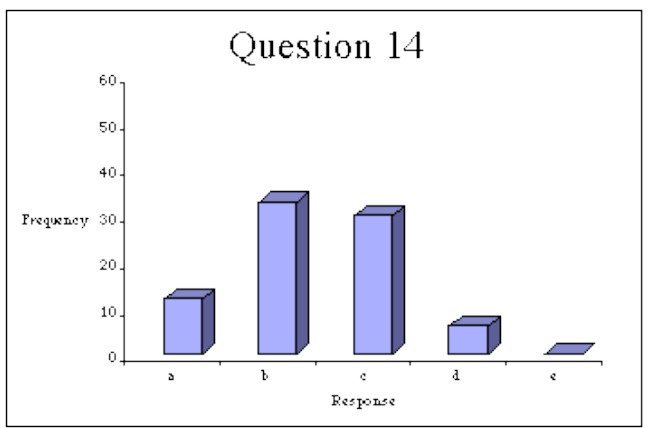

15. Portable document format (.pdf or PDF) file documents are commonly found on the Internet.

a. I have not heard about PDF files.

b. I have heard about, but do not know how to read PDF files.

c. I know how to read PDF files.

d. I have expert knowledge on how to read PDF files.

e. I have sufficient expert knowledge to teach others how to read PDF files.

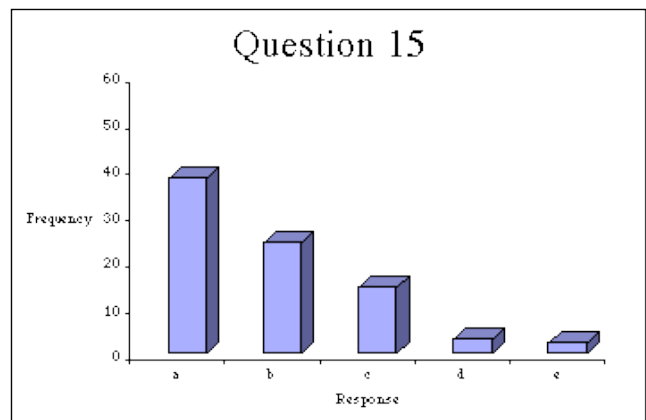

16. Deakin University uses computer conferencing software (eg FIRSTCLASS) for electronic discussion spaces, chatrooms and electronic bulletin boards.

a. I have not heard about computer conferencing software.

b. I have heard about, but do not know how to use computer conferencing software.

c. I know how to use computer conferencing software..

d. I have expert knowledge on how to use computer conferencing software.

e. I have sufficient expert knowledge to teach others how to use computer conferencing.

17. Deakin University has open access computer laboratories for students to use.

a. I have not heard about the open access computer laboratories.

b. I have heard about, but do not know how to use the open access computer labs.

c. I know how to use the open access computer laboratories.

d. I have expert knowledge on how to use the open access computer labs.

e. I have sufficient expert knowledge to teach others how to use the open access computer laboratories. 

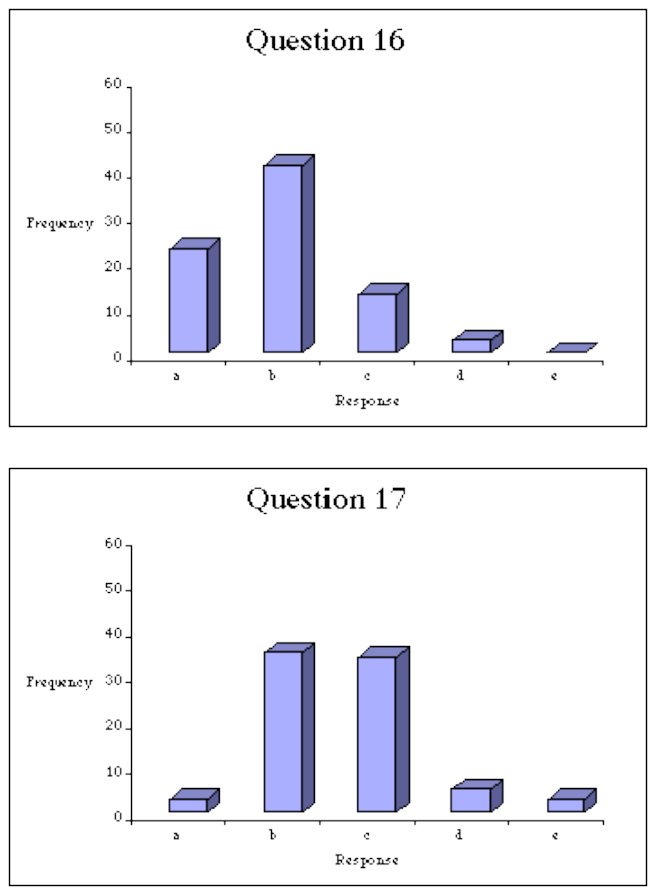

Kieran F. Lim and Jeanne Lee

School of Biological and Chemical Sciences,

Deakin University, Geelong, Victoria 3217, Australia

Email: lim@deakin.edu.au Web: http: / / www.deakin.edu.au/ lim

Kieran Lim obtained his BSc (Hons) and PhD in theoretical chemistry from University of Sydney. He was awarded an Archbishop Mannix Travelling Scholarship to Stanford University and has held Lectureships at the University of New England, the University of Melbourne and Deakin University, where he is currently a Senior Lecturer in Chemical Sciences. He is a Member (MRACI, CChem) and Certified Practising Chemist (CPChem) of the Royal Australian Chemical Institute, and a Member (MACS) and Practising Computer Professional (PCP) of the Australian Computer Society.

Jeanne Lee has a BSc with First Class Honours in organometallic chemistry from University of New England. She has been a tutor at Mary White College within University of New England and a Research Assistant in polymer chemistry at University of Melbourne. She has worked for ICI Australia (now Orica) and is currently a Special Projects Officer at Deakin University. 